\title{
Endurance Training - Science and Practice
}

Edited by Iñigo Mujika. Pp. 328. Donostia. 2012. €151.30. ISBN 978-84-939970-0-7.

I have always had an interest in endurance sports and have been fortunate enough to work with endurance athletes while completing my PhD. Professor Mujika is a well-respected scientist who, apart from his research work, consults with many elite endurance athletes. I was surprised at how excited I was to review a 'textbook'. Professor Mujika has assembled an 'all-star' cast of contributors world-wide, many of whom are well-known experts in their respective fields.

The book certainly did not disappoint, with all the chapters containing summaries of current and up-to-date literature from leaders in their areas of research. Many of the chapters are authored in part by the 'usual suspects' of exercise physiology, but we are also introduced to a few new experts, who will surely become as well known as their co-authors. The clever organisation of the chapters helps with the flow of the book. The first chapter clearly outlines the requirements for endurance performance and sets the scene for the remaining chapters. The following ten chapters (two to eleven) offer the reader practical information on how to optimise endurance performance. These ten chapters include topics of periodisation, quantifying training load, high-intensity training, recovery strategies and tapering. I especially enjoyed the chapters on high-intensity training by Paul Laursen, quantifying training load by Mike Lambert, and recovery by Shona Halson and Christos Argus. This may be because these chapters are closely aligned to my research, but I found them to be well written and practical. Each chapter ends with a summary of the key points covered and contains a full reference list.

The following six chapters cover the physiological responses to endurance training in more detail. The topics covered include: cardiovascular and metabolic adaptations to endurance training, adaptations of skeletal muscle, and hormonal responses to endurance training. These chapters take the reader a little deeper into the physiology of endurance performance on the molecular and cellular level. Coaches should not be put off by this, as the work is well written and presented in a logical manner. These chapters are essential to the understanding of an athlete's response to endurance training.

Chapter 18 covers physiological testing and adaptation to endurance training. It was great to read a chapter on this topic that didn't put all the eggs in the $\mathrm{VO}_{\text {max }}$ basket. Drs Pyne and Saunders emphasise the importance of economy of movement, fat utilisation (glycogen sparing) and peak power output or peak treadmill running speed as important factors related to endurance performance. The authors offer options for both laboratory and field testing as well as maximal and sub-maximal testing. Physiological testing is an important tool for endurance athletes and coaches and assists in the monitoring of training adaptation, training intensity prescription and profiling athletes for specific events.

As a coach myself, I am often asked nutrition-related questions by the athletes I work with. I am an exercise physiologist and coach, sadly not a dietician, and as a result I can't prescribe eating plans or dietary interventions to my athletes. I am sure that there are many endurance coaches in South Africa or all over the world who face the same dilemma. Fortunately, chapter 21 covers nutritional strategies for endurance training and competition. The authors of the chapter, Louise Burke and Gregory Cox, have put all the key points into three easy-to-digest (pun intended) tables, which allow the reader to get an idea of fuelling strategies for exercise and recovery. While this information may not equip the reader with enough knowledge or experience to prescribe a diet or dietary intervention, it should allow you to determine if your athletes are adopting good nutritional habits.

The book also contains five chapters on endurance training and competition in challenging environments, including heat, cold, altitude, areas of high pollution and the effects of longdistance travel. Most athletes will be exposed to one or more of these environmental conditions while training or competing and a coach or physiologist equipped with the knowledge on how to handle these environments will be an asset to any athlete. Once again, the physiological effects of these environments on performance are discussed, as well as strategies to maximise performance in these conditions.

The book is expensive, but I would certainly recommend it to coaches with some background in physiology and any lecturers who may run an undergraduate coaching course. The book covers all the bases of endurance performance that will serve the reader well.

\section{Benoit Capostagno}

PhD Programme

UCT/MRC Research Unit for Exercise Science and Sports Medicine 